\title{
Conservative versus surgical treatment of the cervical and thoracolumbar spine in spinal trauma
}

\author{
M E Brooks MD, A Ohry MD \\ Chaim Sheba Medical Center, Tel Hashomer, Israel.
}

\section{History}

The treatment approach to traumatic injury in the spinal cord injured patient remains one of the areas of controversy in medicine today. The question of operative intervention and stabilization versus conservative management without surgery remains unsettled despite the mountain of published literature. We will review some of this material and hopefully draw some guidelines which will help in the treatment of this unresolved subject.

About 250 years ago, Gorter ${ }^{1}$ appears to be the first person to advocate operative reduction for spinal trauma. In the early 1800 s, Bell ${ }^{2}$ and Cooper were the earliest to argue the opposing viewpoints in the literature concerning the treatment of the injured spinal column. Postural reduction was advocated by Malgaigne ${ }^{3}$ at about the same time. From then until today the literature is filled with this controversy, with Guttmann ${ }^{4}$ and the Stoke Mandeville group representing the extreme of conservative therapy, and Holdsworth ${ }^{5}$ holding forth on the surgical side. The discussion continues today with a plethora of articles each extolling a particular viewpoint and each claiming superior results.

Before one can understand all of the problems of instability, the normal spine and spinal cord relations must be known. Holdsworth $^{5}$ has written the best description and classification of the traumatic bone injuries to the spinal column based upon mechanism of injury. Bedbrook and Sedgely ${ }^{6}$ make the point that the additional stabilisation of the spinal column is contributed to by the paraspinal musculature. The innervated muscle can regenerate and resume its function after injury. Surgical procedures may destroy this added stabilis- ing factor and in turn further weaken an already weakened system. Here, Bedbrook ${ }^{6}$ makes a very strong case for the conservative approach to the treatment of spinal injury.

The skeletal injury may or may not be associated with abnormal neurological findings. Unfortunately the forces necessary to generate skeletal injuries are also great enough to damage the spinal cord either directly, by damage to the blood supply to the cord, as a result of the skeletal disarrangement, or through a combination of these factor. The injury may be complete or incomplete, purely motor or purely sensory, or a combination of these.

Guttmann, ${ }^{4}$ Hardy, $^{7}$ and Holdsworth ${ }^{5}$ have all emphasised the importance of the initial neurological examination in determining the exact location and extent of the neurological damage. There is no correlation between the neurological loss and the skeletal trauma. It is most important to document any neurological sparing below the level of the trauma. On the other hand, a vascular lesion above the level of the skeletal trauma will show a neurological picture very different from that of the expected findings at the level of the skeletal damage. The sooner after trauma this initial examination is performed, the more valuable it becomes in determining the treatment programme and prognosis. Any deterioration of the neurological condition may not be noted and the neurological finding seen at the initial examination may be accepted as the neurological picture resulting from the trauma, when in fact the initial picture was an evolving sequence which was never detected. This can have serious implications for treatment and regarding the final clinical outcome. The 
neurological examination must be repeated at intervals to assess the clinical status and to change the treatment as may be indicated.

The initial neurological examination is also the basis for the radiological studies which determine the extent of skeletal damage if any, and its treatment. The most important radiological studies of the spine are the lateral views. This is followed by the anterior-posterior views. Further radiological studies, CT Scan, tomography, special view, etc, will depend upon the findings in the initial films. It must be kept in mind, that the greater the number of studies, the more frequent the transfers and the greater the delay.

\section{Conservative approach}

Any discussion of the treatment of patients with spinal cord injuries must distinguish between the skeletal injury and the neurological damage. Treatment of the skeletal injury is based upon the principle of dislocation reduction and anatomical approximation, without causing or increasing any neurological damage. Hopefully this will result in a stable situation without complications.

The conservative (non operative) approach is based on closed reduction maintained by proper posturing and contra-forces generated by using pillows or packs placed opposite the fracture site. With skilled nursing care and patience, these fractures will reduce and stabilise with bony bridges above and below the fracture level. Using the conservative approach, Frankel et $a l^{8}$ reported on the treatment of 612 patients with closed spinal injuries. Fracturedislocations took approximately 12 weeks of conservative postural reduction and positioning with only 4 patients having unstable spines after the initial treatment. Guttmann,${ }^{4}$ in his book on spinal cord injuries, describes the proper posturing and methods for closed reduction of a spinal cord injured patient. According to Bedbrook ${ }^{6}$ 'stability' is rapidly achieved within 2 to 3 weeks.

The areas of the cervical and thoracolumbar junctions are the 2 problem areas for achieving stability. In patients with cervical injuries with a dislocation, cervical traction with sufficient distraction to reduce the dislocation (we have used up to $75 \mathrm{~kg}$ to reduce interlocking facets) is needed. Maintenance of the normal cervical anatomy using cervical traction with one of the several available calipers (Cone, Cruchfield, Vinke etc), and with a small 'sausage' pillow placed posteriorly to the fracture site is enough to reduce and maintain the injured area in an anatomical relationship and give the area a chance to stabilise. Halo stabilisation as described by Nickel et $a l^{9}$ is another method of immobilisation with the added element of early ambulation wearing this apparatus. Rocksworth et $a l^{10}$ showed that in hyperflexion-anterior subluxation injuries there is a relatively high rate of failure to achieve stability with the halo device. In other types of fracture, the success rate is better. The same principles apply to the thoracolumbar area. Here the facture picture is different with much less in the way of an accompanying dislocation. Postural reduction will result in a healed fracture in good alignment. If this is the goal, this is the method of choice. There is no hurry in attempting to treat surgically a seemingly unstable fracture, which may indeed stabilise after extended non surgical treatment. The main apparent drawback seems to be the long time of immobilisation that is necessary. This, however, is not a time loss nor as the insurance companies believe, an unnecessary expense. With prolonged rest, the patient has the opportunity to adapt both psychologically and socially to his new condition whilst in a hospital setting with a fully trained professional staff to support him.

\section{Surgical treatment}

The surgical treatment of the injured spine has indeed progressed from the early doctrine that only complete restoration of the normal anatomical relationships will ensure neurological recovery. Nicoll $^{11}$ was the first orthopaedist to disprove this thesis. The development of late deformation led to the idea of early operation to provide good alignment and internal fixation. The surgical treatment must be carefully considered, 
because there are different problems for the cervical and thoracolumbar areas. Each anatomical area presents a plethora of ideas, operations, equipment and procedures, all of which are specifically tailored to the particular problems of either the cervical or the thoracolumbar region.

In the cervical spine area the main problem is one of a fracture with an associated dislocation. Here the the main question is whether the anterior or the posterior approach will give better results for the reduction and the stabilisation procedure. The internal fixation device used will depend upon the approach. In both approaches a bone graft of some type is used: in the anterior approach to replace displaced intervertebral disc material and achieve an interbody fusion; and in the posterior approach an inlay graft is used to achieve the same result. This decision is dictated by the fracture level and aetiology, the stability, the condition of the patient and the skill of the surgeon. An excellent review of this material can be found in Surgery in Spine Trauma by Paul R Meyer. ${ }^{12}$

The main problem in the thoracolumbar area is one of pain and late deformity. The internal fixation devices include wire loops, plates, springs, methylmethacrylate and varying rod reinforcements. Prediction of the trauma population which will develop these deformities or whose fractures will be unstable is impossible. Each seperate system and device has its advocates who are certain that their system is the most effective. The secondary rationalisation for immediate surgery is the shortening of hospitalisation which is greatly supported by the pressure of the third party payees to reduce the hospitalisation costs. A surgical procedure which will do this is certainly worthwhile. Neurological improvement is unaffected by any of these stabilisation procedures when compared to the non operative treatment methods. Gertzbein et al ${ }^{13}$ and Davies et al ${ }^{14}$ have confirmed these findings in their series.

\section{Pharmacological agents in neurological trauma}

Many pharmacological substances have been tried to achieve improvement in recovery and function in the traumatically injured spinal cord. Faden ${ }^{15}$ has reviewed the use of varying factors which may cause the secondary (post ischaemic) damage to the spinal cord. These include free radicals, neuropeptides arachionic acid metabolites, extracellular calcium changes, membrane disruption, and 'autodestructive' factors. $\mathrm{He}$ later showed that opiate antagonists improve neurological recovery after spinal injury in cats. Haghighi and Chehrazi ${ }^{16}$ found no effect in experimental acute spinal cord trauma. De la Torre and Goldsmith ${ }^{17}$ have attempted to increase blood flow to enhance axon reveneration after experimental cord transection by the operation of omental transplantation. Marcus et al ${ }^{18}$ have studied the regulation of total and regional spinal cord blood flow. Salzman et al ${ }^{\text {19 }}$ have investigated the role of monoaminergic responses to spinal trauma and have shown the continued presence of significant serotonin activity in the traumatised cord up to 6 weeks post injury. His group has also shown experimentally that the activity of immunoreactive thyroid releasing hormone is altered in the spinal cord after local spinal trauma. They postulate that antagonists of these substances may well change the neurological picture after trauma. In most of these examples the work has been experimental, in laboratory animals. As of late 2 reports have been published showing clinical applications of some of these ideas. The randomised study on methylprednisolone in spinal cord injury showed that early administration of this steroid does indeed improve neurological recovery. Geisler et $a l^{20}$ also reported on the recovery function following spinal cord injury after the adminstration of GM-1 ganglioside. These studies are really preliminary findings and much work must still be done. We would refer to the editorials in the Lancet and in the New England Journal of Medicines.

Perhaps this work will result in the initial pharmacological therapy outweighing the emphasis on the stability or instability of the skeletal injury, thus ending the controversy once and for all. In summary we can say that almost without exception there is no place 
for surgical intervention for patients with a traumatic spinal cord injury, except when there is rapid neurological deterioration in the face of the administration of methylprednisone. Late stabilisation procedures must be judged on an individual basis depending on pain, deformity, and patient discomfort.

Predictions for the future and the types of future treatment are always wrong. Suffice it to say that the solution to spinal cord trauma will include surgery of some sort for stabilisation and conservative treatment to allow time for neuroregeneration.

\section{References}

1 Gorter (1742) Chirurgia repurgata. Lugduni Batav 8: 377.

2 Bell C (1807) A System of Operative Surgery. Longman and Co, London: 132.

3 Malgaine, J (1847) Traite des Fractures et des Luxations Paris 1847: Vol I 410; Vol II 318.

4 Guttmann L The Conservative Management of closed injuries of the vertebral column resulting in damage to the spinal cord and spinal roots. In: Vinken PJ, Bruyn GW, eds. Handbook of Clinical Neurology. Vol 26, part II. North-Holland Publishing Co, Amsterdam.

5 Holdsworth F (1970) Fractures, dislocations, and fracture-dislocations of the spine. J Bone Joint Surg 52A; 1134-1151.

6 Bedbrook GM, Sedgely GI (1980) The management of spinal injuries - past and present. Int Rehabil Med 2: $45-61$.

7 Frankel H, Hancock DO, Hyslop G et al (1969) The value of postural reduction in the initial management of closed injuries in the spine with paraplegia and tetraplegia, Paraplegia 7: 171-192.

8 Nickel VL. Perry J \& Garrett A et al (1968) The halo: a spinal skeletal traction fixation device JBJS 50A: 1400-1409.

9 Burke DC \& Murray DD (1976) The management of thoracic and thoraco-lumbar injuries of the spine with neurological involvement, JBJS, 58B: 72-78.

10 Donovan WH, Kopaniky D, Stolzmann E \& Carter ER (1987) The neurological and skeletal outcome in patients with closed cervical spinal cord injury, J Neurosurg. 66: 690-694.

11 Nicoll EA (1949) Fractures of the dorso-lumbar spine, JBJS, 31B: 376-394.

12 Morgan TH, Wharton GW \& Austin GN (1971) The results of laminectomy in patients with incomplete spinal cord injuries, Paraplegia, 9: 14-23.

13 Murphy KP, Opritz JL, Cabanela ME \& Ebersold MJ (1990) Cervical fractures and spinal cord injury, Mayo Clin. Proc. 65: 949-959.

14 Kaye JJ \& Nance EP (1990) Cervical spine trauma, Orthopedic Clinics of North America, 21: 449-462.

15 Allen BL, Tencer AF \& Ferguson RL (1987) The biomechanics of decompressive laminectomy, Spine 12: $803-808$.

16 Meyer PR \& Heim S (1989) Surgical stabilization of the cervical spine, in: Surgery of Spine Trauma, Meyer PR, Churchill Livingstone, New York.

17 Dickson JH, Harrington PR \& Erwin WD (1978) Results of reduction and stabilisation of the severely fractured thoracic spine, JBJS, 60A: 799-805.

18 Luque ER, Cassis N \& Ramirez-Wiella G (1982) Segmental spine instrumentation in the treatment of fractures of the thoracolumbar spine, Spine, 7: 312 .

19 Yosipovich Z, Robin GC \& Makin M (1977) Open reduction of thoracolumbar spinal injuries and fixation with Harrington rods, JBJS. 59A: 1003-1015.

20 Gertzbein SD, Machmichael D \& Tile M (1980) Harrington instrumentation as a method of fixation in fractures of the spine, JBJS. 64B: 526-529.

21 Faden AI (1987) Pharmacotherapy in spinal cord injury: a critical review of recent developments. Clin. Neuropharmacol. 10 (3): 193-204.

22 de la Torre JC \& Goldsmith HS (1990) Collagen-omental graft in experimental spinal cord transection, Acta Neurochirg (Wien) 102: 152-163.

23 Marcus, ML, Heistad DD, Ehrhardt JC \& Abboud FM (1977) Regulation of total and regional spinal cord blood flow, Circ. Res. 41: 128-134.

24 Salzman SK, Hirofuji E, Llados-Eckman C et al (1987) Monoamine responses to spinal trauma, J Neurosurg 66: 431-439.

25 Bracken MB, Shepard MJ, Collins WF et al (1990) A randomized, controlled trial of methylprednisolone or Naloxone in the treatment of acute spinal-cord injury, NEJM 322: 1405-1411.

26 Geisler FH, Dorsey DC \& Coleman WP (1991) Recovery of motor function after spinal cord injury-a randomized, placebo-controlled trial with GM-1 ganglioside. NEJM 324: 1829-1837.

27 Editorial (1990) Steriods after spinal cord injury, Lancet 336: 279-280.

28 Walker MD (1991) Editorial, Acute spinal cord injury, NEJM 324: 1829-1885-1887. 